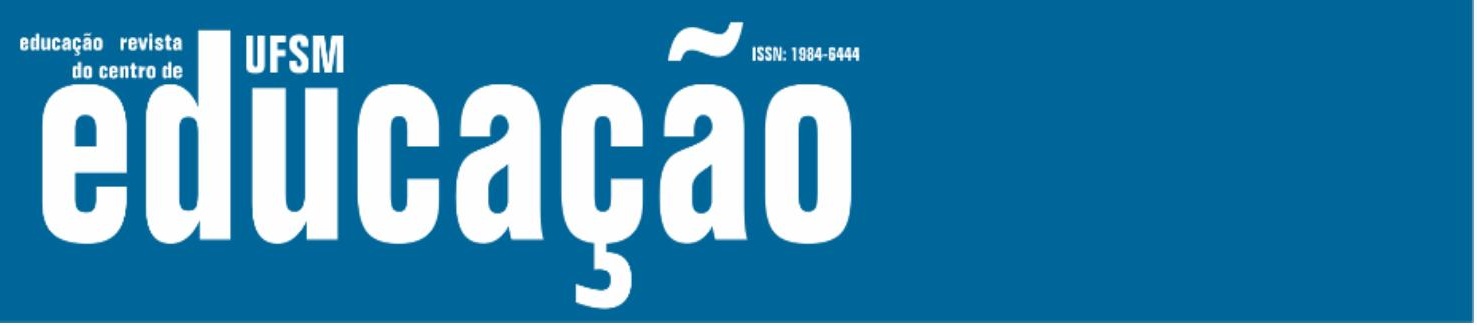

ISSN: 1984-6444 | http://dx.doi.org/10.5902/1984644436687

\title{
A perspectiva da abordagem qualitativa narrativa de cunho sociocultural: possibilidade metodológica na pesquisa em educação
}

The perspective of the narrative qualitative approach of sociocultural slant: methodological possibility in education research

Juliana Lima Moreira Rhoden

Professora doutora na Universidade Federal do Pampa, Campus São Borja. São Borja, Rio Grande do Sul, Brasil.

juli.rhoden@gmail.com - https://orcid.org/0000-0002-7251-1067

\section{Silvana Zancan}

Professora doutora na Universidade Federal de Santa Maria. Santa Maria, Rio Grande do Sul, Brasil. silvanazancan@hotmail.com - https://orcid.org/0000-0003-4203-1772

Recebido em 31 de janeiro de 2019

Aprovado em 13 de novembro de 2019

Publicado em 24 de junho de 2020

\section{RESUMO}

A partir de uma discussão teórica, este artigo busca apresentar reflexões sobre a abordagem qualitativa narrativa de cunho sociocultural, como possibilidade metodológica na pesquisa em educação. Para isso, inicialmente, a proposta é introduzir a discussão tecendo algumas considerações sobre a pesquisa qualitativa, para, posteriormente, abordar sobre a possibilidade de investigação pela abordagem narrativa sociocultural. Sendo assim, o objetivo principal é refletir sobre algumas concepções teóricas desta perspectiva de investigação. Trata-se de uma abordagem que vem contribuindo para o avanço das pesquisas em educação, principalmente em relação às temáticas que envolvem o estudo sobre aprendizagem docente, atividade docente de estudo, construção do conhecimento pedagógico, desenvolvimento profissional, trajetórias e saberes docentes na educação básica e superior. Portanto, as investigações baseadas nessa abordagem possibilitam a compreensão do processo de transformação, sob seu aspecto histórico e de mudança, no qual os sujeitos que narram estão envolvidos.

Palavras-chave: Abordagem qualitativa; Narrativa de Cunho Sociocultural; Pesquisa em Educação. 


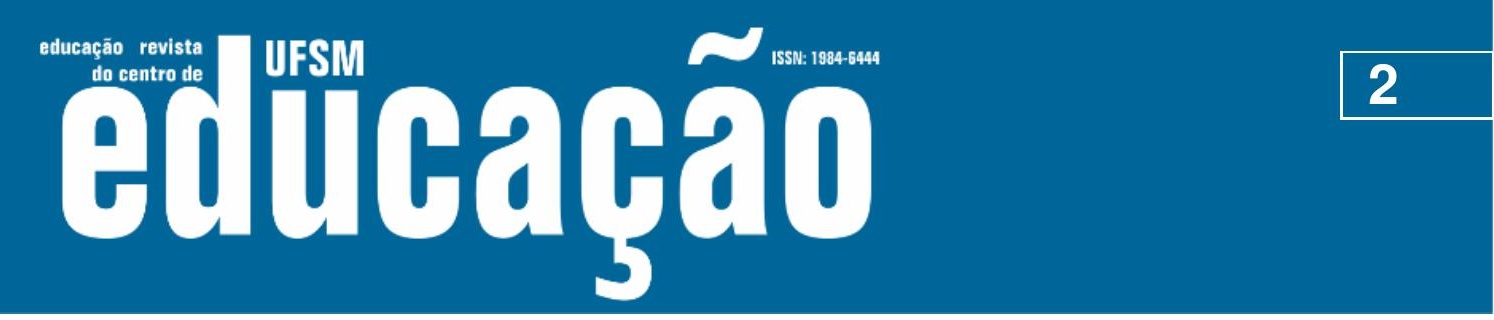

ISSN: 1984-6444 | http://dx.doi.org/10.5902/1984644436687

\section{ABSTRACT}

From a theoretical discussion, this article seeks to present reflections on the qualitative narrative approach of sociocultural slant, as a methodological possibility in education research. To this end, the proposal is to introduce the discussion by making some considerations about qualitative research, and later to discuss the possibility of research by the sociocultural narrative approach. Therefore, the main objective is to reflect on some theoretical conceptions of this research perspective. It is an approach that has contributed to the advancement of research in education, especially in relation to the themes that involve the study on teacher learning, teaching activity of study, construction of pedagogical knowledge, professional development, trajectories and teacher knowledge in basic education and higher. Therefore, investigations based on this approach make it possible to understand the transformation process, under its historical and change aspect, in which the subjects who narrate are involved.

Keywords: Qualitative approach; Sociocultural Narrative; Education research.

\section{Introdução}

$\mathrm{Na}$ atualidade, os métodos qualitativos vêm ganhando cada vez mais importância e são praticados em diferentes contextos institucionais e pelos grupos de pesquisa, sobretudo nos programas de pós-graduação em educação. Por isso, objetivamos apresentar reflexões sobre a abordagem qualitativa narrativa de cunho sociocultural, como possibilidade metodológica na pesquisa em educação.

As pesquisas qualitativas aparecem para dar conta do lado não visível e não compreendido apenas por meio de equações, médias e estatísticas, ou seja, nas pesquisas qualitativas, o pesquisador preocupa-se com aspectos da realidade que não podem ser quantificados, centrando-se na compreensão e na explicação da dinâmica das relações sociais. Os princípios da pesquisa qualitativa, como apontam Gergen e Gergen (2006, p. 367) proporcionam "uma das mais ricas e compensadoras explorações disponíveis na ciência social contemporânea", mesmo que estejam ainda diante de tensões, contradições, hesitações e transformações.

Nas acepções de Gatti e André (2011, p. 30), a pesquisa qualitativa "busca a interpretação no lugar da mensuração, a descoberta no lugar da constatação, e assume que fatos e valores estão intimamente relacionados", não sendo possível 


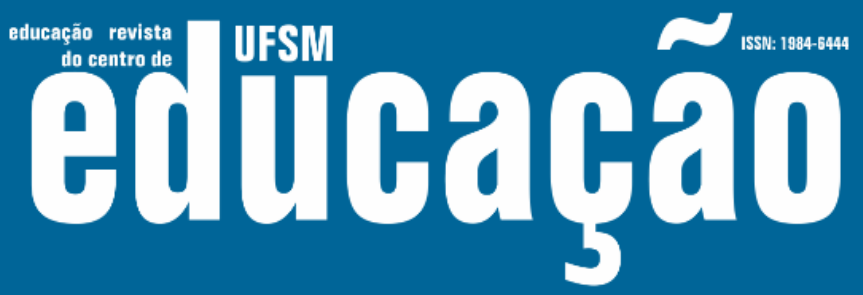

ISSN: 1984-6444 | http://dx.doi.org/10.5902/1984644436687

uma postura neutra do pesquisador. Segundo as autoras, a abordagem qualitativa defende uma visão holística dos fenômenos, que leve em consideração todos os componentes de uma situação em suas interações e influências recíprocas.

Para Minayo (2001), a pesquisa qualitativa trabalha com o universo de significados, de motivos, de aspirações, de crenças, de valores e de atitudes, o que corresponde a um espaço mais profundo das relações, dos processos e dos fenômenos que não podem ser reduzidos à operacionalização de variáveis. A autora ainda acrescenta que a pesquisa qualitativa "[...] responde a questões muito particulares [...] com um nível de realidade que não pode ser quantificado (MINAYO, 2001, p. 22)".

$\mathrm{Na}$ perspectiva das pesquisas qualitativas, todo tema pode ser considerado inédito, uma vez que um mesmo fato pode ser abordado por determinado pesquisador segundo a visão de um referencial ou com base em um método que ainda não tenha sido contemplado em outras pesquisas. Isso, por si só, já garante uma riqueza de significados.

Já o autor Gonzalez Rey (2002, p. 28), ao se referir à abordagem qualitativa em pesquisa, aponta:

Em primeiro lugar, a ciência não é só racionalidade, é subjetividade em tudo
o que o termo implica, é emoção, individualização, contradição, enfim, é
expressão íntegra do fluxo da vida humana, que se realiza através de
sujeitos individuais, nos quais sua experiência se concretiza de forma
individualizada de sua produção. O social surge na rota única dos indivíduos
constituídos em uma sociedade e uma cultura particular.

A pesquisa qualitativa abrange uma pluralidade de pontos de vista epistemológicos e teóricos e pressupõe uma grande variedade de técnicas e uma multiplicidade de objetos pesquisados. É preciso especificar que a própria pesquisa qualitativa se divide em várias correntes, cada uma tendo uma perspectiva própria.

Nas ciências humanas e sociais, em que se situa a ciência da educação, a pesquisa qualitativa ocupa lugar de destaque, pois assegura uma abordagem na qual a compreensão e a interpretação são mais importantes do que a descrição ou a explicação de um fenômeno. Isso significa que, na pesquisa em educação, interessa 


\section{T usm

ISSN: 1984-6444 | http://dx.doi.org/10.5902/1984644436687

A abordagem qualitativa narrativa sociocultural tem como uma das propostas dar voz aos sujeitos investigados, por meio da entrevista narrativa, o que possibilitará fazer a análise da atividade discursiva/narrativa ${ }^{1}$ dos professores. Como aponta Bolzan (2009a, p.73):

O aspecto principal da abordagem sociocultural através da narrativa está na compreensão de que se está vivendo em um contínuo contexto experencial, social e cultural, ao mesmo tempo, que contamos nossas histórias, refletimos sobre nossas vivências, explicitando a todos os nossos pensamentos, através de nossas vozes. Somos sujeitos históricos, datados, concretos, marcados por uma cultura, os quais criam ideias e consciência ao produzir e reproduzir a realidade social, sendo nela, ao mesmo tempo, produzidos e reproduzidos.

Este tipo de investigação coloca o sujeito/colaborador da pesquisa como protagonista da investigação, mostrando que ele possui voz e é capaz de refletir sobre suas ações, bem como é ativo, social e histórico.

Por meio da análise da atividade discursiva/narrativa entre os professores é possível fazer uma leitura dos significados das atividades dos docentes. Essa abordagem implica a compreensão do processo de transformação no qual os participantes da investigação explicitam suas ideias revelando a subjetividade/objetividade das relações sociais vividas na docência (BOLZAN, 2006, p. 386).

Quando utilizamos a abordagem narrativa sociocultural, estamos realizando um estudo qualitativo que comporta uma análise que centra sua atenção nos processos de construção coletiva, com base na realidade sociocultural dos sujeitos participantes do processo (BOLZAN, 2001, 2002). Nesse sentido é importante a compreensão dentro de uma determinada situação histórica e cultural, visto que é resultado de uma construção conjunta.

A perspectiva da pesquisa de caráter sociocultural é edificada em coerência com alguns pressupostos teóricos vygotskianos e bakhtianos, intitulados de abordagem sócio-histórico-cultural. Vygotsky (1995) e Bakthtin (2009) tiveram como base o materialismo histórico dialético e, a partir dele, construíram uma visão abrangente, não vendo a realidade como algo em pedaços, fragmentada, e sim a enxergando dentro de uma visão totalizante, compreendendo o homem em seu conjunto de relações sociais, pela sua inserção em determinada sociedade, em um momento histórico específico. 


\section{ON Hism Autlbahat}

ISSN: 1984-6444 | http://dx.doi.org/10.5902/1984644436687

O materialismo dialético entende que não existem oposições dualistas/dicotômicas entre as instâncias sociais e individuais, objetividadesubjetividade, interno-externo. É pela dialética apropriação/objetivação - o processo através do qual o sujeito internaliza (e objetiva) o significado das experiências de suas atividades no mundo - que ele se torna histórico. Portanto, ao se apropriar de uma objetivação, o sujeito está se relacionando com a história social, ainda que essa relação não venha a ser percebida conscientemente por ele.

[...] estudiar algo históricamente significa estudiarlo en movimiento. Esta es la exigencia undamental del método dialéctico. Cuando en una investigación se abarca el proceso de desarollo de algún fenómeno en todas sus fases y cambios, desde que surge, hasta que desaparece, ello implica poner de manifiesto su naturaleza, conocer su esencia, ya que sólo en movimiento demuestra el cuerpo que existe. Así pués, la investigación histórica de la conducta no es algo que complementa o ayuda el estudio teórico, sino que constituye su fundamento. (VYGOTSKY, 1995, p. 67-68) ${ }^{2}$

Para o autor, estudar alguma coisa historicamente significa estudá-la no processo de mudança e de movimento; esse é o requisito básico do método dialético. Pela importância que deu aos métodos de pesquisa, ele pode ser considerado também um metodólogo. Nessa perspectiva, afirma a necessidade de se estudar a dimensão histórica, o que não significa analisar simplesmente os eventos passados, mas compreender o processo de transformação do presente implicado nas condições passadas e nas projeções do futuro, o que implica estudar o fenômeno em seu processo vivo e não estático, pois todo o fenômeno tem a sua história.

Na visão do autor, não há como compreender o indivíduo sem conhecer o seu mundo, pois sujeito e mundo são, assim, âmbitos distintos, mas criados no mesmo processo. Como aponta Bock (2007), falar de subjetividade humana é falar da objetividade em que vivem os homens. A compreensão do mundo interno exige também a compreensão do mundo externo, pois estes são dois aspectos de um mesmo movimento, de um processo no qual o homem atua e constrói/modifica o mundo, e este, por sua vez, propicia os elementos para a constituição psicológica do homem. 


\section{Autนaดูลิ}

ISSN: 1984-6444 | http://dx.doi.org/10.5902/1984644436687

determinados histórica e socialmente e, diante disso, não podemos desconsiderar a relação do sujeito com o seu mundo social.

\section{A narrativa na abordagem sociocultural: dando voz aos colaboradores da pesquisa}

Uma das propostas deste tipo de investigação é dar voz aos sujeitos investigados, o que possibilita fazer a análise da atividade discursiva/narrativa dos colaboradores da pesquisa. A história, as experiências e as vivências dos colaboradores de uma pesquisa estão marcadas pelo percurso construído por eles ao longo de uma trajetória, esta que deve ser cuidadosamente "olhada" de maneira responsiva, a fim de produzir sentido e significado para aquele que pesquisa e para o sujeito colaborador da pesquisa. Desse modo, a abordagem investigativa pautada em narrativas socioculturais permite ao pesquisador compreender o fenômeno investigado mediante seu processo de transformação, seu movimento e seu aspecto sociocultural.

A abordagem investigativa pautada em narrativas socioculturais conta como instrumento de coleta de dados, a entrevista narrativa. Para Bakhtin (2011) na entrevista narrativa, a palavra é à base do discurso. Por isso, as perguntas abertas e é uma forma de encorajar os entrevistados a relatar seus pensamentos e opiniões. A ideia básica de acordo com esse autor é que no discurso, o sujeito constrói relações com o contexto em que vive e os modifica, conforme as situações culturais e históricas que se apresentam. Bakthin (2011, p. 275) elucida que:

\footnotetext{
Os limites de cada enunciado concreto como unidade da comunicação discursiva são definidos pela alternância dos sujeitos do discurso, ou seja, pela alternância dos falantes. Todo enunciado da réplica sucinta (monovocal) do diálogo cotidiano ao grande romance ou tratado científico tem, por assim dizer, um princípio absoluto e um fim absoluto. [...] O falante termina o seu enunciado para passar a palavra ao outro ou dar lugar à sua compreensão ativamente responsiva.
}

Logo, a materialização da comunicação está associada aos fatores históricos e sociais que permeiam as relações entre as pessoas. Diante dessa perspectiva, a entrevista narrativa é dialógica, não se reduz a troca de perguntas e respostas de antemão preparadas, é entendida como um espaço de produção de linguagem. A 


\section{Usism Autlbahat

ISSN: 1984-6444 | http://dx.doi.org/10.5902/1984644436687

entrevista gera uma parceria efetivada na experiência dialógica entre pesquisador e pesquisado, mostrando-se como método de pesquisa com sujeitos e não sobre sujeitos (FREITAS, 2002).

Partindo dessa premissa, as entrevistas não são organizadas em forma de perguntas estruturadas, mas a partir de tópicos guias. Os sentidos são criados a partir do diálogo e da comunicação entre o pesquisador e o entrevistado. Nesse sentido, a investigação narrativa estrutura:

[...] tanto a experiência que será estudada quanto os padrões de investigação que são utilizados para seu estudo. Tal procedimento compreende, não só como os atores relatam suas vidas (pessoal e profissional), mas também como os pesquisadores narram esses relatos. As duas narrativas, a do participante e a do pesquisador, convertem-se em uma construção/reconstrução narrativa compartilhada (ISAIA, 2006, p. 385).

Desse modo, a investigação narrativa, compreende uma característica colaborativa, pelo fato de emergir a partir da interação entre entrevistador e entrevistado. Um elemento importante é a base epistêmica da entrevista, que se caracteriza pelo estudo sócio-histórico vygotskiano e também pelos estudos bakhitianos. Esses autores abordaram a linguagem como processo de expressão e de criação do homem, relacionado à cultura e à história, atribuindo valor à palavra e à interação com o outro.

Como aponta Bakhtin (2009), a linguagem é uma prática social que envolve a experiência do relacionamento entre sujeitos e que tem na língua a sua realidade material. Trata-se de uma fala que não é individual, mas social e está ligada à enunciação. Nessa perspectiva, podemos compreendê-la a partir de sua teoria da enunciação, uma vez que é na enunciação que as "palavras" dirigem-se a outrem, externamente.

Toda palavra comporta duas faces. Ela é determinada tanto pelo fato de que procede de alguém, como pelo fato de que se dirige para alguém. Ela constitui justamente o produto da interação do locutor e do ouvinte. Toda palavra serve de expressão a um em relação ao outro, isto é, em última análise, em relação a coletividade. A palavra é uma espécie de ponte lançada entre mim e os outros. Se ela se apóia sobre mim numa extremidade, na outra se apóia sobre o meu interlocutor. A palavra é o território comum do locutor e do interlocutor (BAKHTIN, 2009, p.117). 


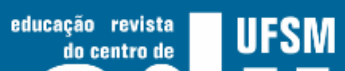 Autlbahat

ISSN: 1984-6444 | http://dx.doi.org/10.5902/1984644436687

Bakhtin considerou o enunciado como a verdadeira unidade de comunicação verbal, que só pode existir se é produzido por uma voz. Um enunciado reflete, além da voz que o produz, as vozes a quem ele se dirige (WERTSCH, 1993).

Além disso, com fundamento nos conceitos bakhtinianos, entender a linguagem como discurso requer não só que o conteúdo do enunciado seja considerado, mas, sobretudo, saber em que contexto se insere aquilo que é dito e de que modo o dizer se produz.

$\mathrm{Na}$ interlocução, as pessoas discutem um assunto e determinam um sentido para aquilo que falam. A relação que se estabelece com os sujeitos colaboradores da pesquisa pode propiciar o espaço para a produção de sentidos e permite ao pesquisador a identificação de vivências significativas na trajetória dos professores que os mobilizaram a (re)investir na profissão.

$\mathrm{Na}$ abordagem narrativa sociocultural, a entrevista narrativa, como instrumento de coleta de dados, caracteriza-se por analisar a atividade narrativa dos sujeitos participantes desse processo, tendo como base a realidade sociocultural que thes é específica, ou seja, os ditos/falas/vozes/narrativas constituem-se em material fundamental da consciência, revelando-se produto da interação entre os indivíduos durante a comunicação. A palavra passa a constituir o meio pelo qual se produzem modificações sociais (BOLZAN, 2009a).

A palavra expressa é carregada de "significado" e de "sentido". Para Vygotsky (2008, p. 125),

[...] o sentido de uma palavra é a soma de todos os fatos psicológicos que ela desperta em nossa consciência. Assim, o sentido é sempre uma formação dinâmica, fluída, complexa, que tem várias zonas de estabilidade variada. O significado é apenas uma dessas zonas do sentido que a palavra adquire no contexto de algum discurso e, ademais, uma zona mais estável, uniforme, exata. Como se sabe, em contextos diferentes a palavra muda facilmente de sentido. O significado, ao contrário, é um ponto imutável que permanece estável em todas as mudanças de sentido da palavra em diferentes contextos $[\ldots]$.

sentido se produz no contexto da interlocução, enquanto o significado é mais estável e precisa do sentido. O enriquecimento das palavras, que é dado pelo sentido a partir do contexto, é a lei fundamental da dinâmica do significado das palavras. 


\section{$\sim$ ussm,

ISSN: 1984-6444 | http://dx.doi.org/10.5902/1984644436687

Bolzan (2009a, p.73) afirma que:

Um dos aspectos mais importantes do uso das narrativas na investigação é o fato de enfocarmos a voz do sujeito que é narrado e a voz de quem o narra. Os relatos revelam as múltiplas vozes entrelaçadas durante a narração, devendo explicitar sua estrutura através da descrição do cenário e da trama, localizados em um tempo e um espaço.

O trabalho, nesse viés, permite a compreensão de como os enunciados entre si produzem sentido e significado para aquele que narra (o entrevistado/sujeito da pesquisa) e para aquele que pergunta (o entrevistador/pesquisador). Vygotsky (2008 p. 125) faz uma diferenciação entre o sentido e o significado da palavra, afirmando que "[...] o sentido de uma palavra é a soma de todos os eventos psicológicos que a palavra desperta em nossa consciência [...]. O significado é apenas uma das zonas de sentido, a mais estável e precisa". Para o autor, mediante a palavra, surgem diversos significados, os quais são transformados em sentidos pessoais, de acordo com as necessidades e as emoções que motivaram sua expressão. Assim, entendemos que os significados das palavras compõem a consciência individual, mas são, ao mesmo tempo, construídos no âmbito interindividual e têm um caráter social.

O que resulta do que é narrado pelo entrevistado/sujeito da pesquisa, ou seja, do seu processo autorreflexivo, que muitas vezes só é constituído pela sua experiência de narrar, vai possibilitar ao pesquisador/entrevistador uma compreensão a luz da teoria escolhida como base de seu estudo, na medida em que olha para o conjunto de enunciados trazidos pelos entrevistados e do que eles trouxeram da sua realidade socio-histórico-cultural.

Estamos diante de uma investigação narrativa que, de acordo com Isaia (2006, p. 385):

É o estudo da forma como os professores e os demais atores da cena educativa experimentam o mundo e o reconstroem, por meio dos fios da memória. A complexidade dessa investigação está em que uma mesma pessoa encontra-se simultaneamente ocupada em viver, explicar e reviver sua história. Vida e narrativa são momentos que se interpenetram no fluxo da existência ao dar sentido a ela e reconstruí-la ao narrá-la. (ISAIA, 2006, p. 385) 


\section{Lism Aitlbahat

ISSN: 1984-6444 | http://dx.doi.org/10.5902/1984644436687

Freitas e Ramos (2010, p. 9) apontam que, em uma pesquisa, a fonte de dados é sempre o texto e que, para compreender seu objeto, outro sujeito, o pesquisador, necessita compreender o texto desse sujeito, que pode ser entendido por suas falas, escrituras e gestos; aquilo que de alguma maneira emana um sentido. Como aponta Bakhtin (2011, p. 308), "todo texto tem um sujeito, um autor (o falante, ou quem escreve)", "o acontecimento da vida do texto, isto é, a sua verdadeira essência sempre se desenvolve na fronteira de duas consciências, de dois sujeitos" (BAKHTIN, 2010, p. 311). Desse modo, compreendemos esta relação como dialógica e aberta, onde pesquisador e pesquisado se expressam e produzem sentidos e significados para si e para o outro.

A pergunta que o pesquisador faz na narrativa permite que o entrevistado possa primeiramente fazer sentido para si e, consequentemente, para o pesquisador que vai trabalhar com os dados (a narrativa), do ponto de vista da teoria e olhando para o contexto sócio-histórico. Bakhtin (2011) entende que só pode haver significado quando duas ou mais vozes entram em contato e acrescenta:

[...] o ouvinte, ao perceber e compreender o significado (linguístico) do discurso ocupa simultaneamente em relação a ele uma ativa posição responsiva: concorda ou discorda dele (total ou parcialmente), completa-o, aplica-o, prepara-se para usá-lo, etc; essa posição responsiva do ouvinte se forma ao longo de todo o processo de audição e compreensão desde seu início, ás vezes literalmente a partir da primeira palavra do falante. Toda compreensão da fala viva, do enunciado vivo é de natureza ativamente responsiva (embora o grau desse ativismo seja bastante diverso); toda compreensão é prenhe de resposta, e nessa ou naquela forma a gera obrigatoriamente: o ouvinte se torna falante.

A compreensão de um enunciado, segundo Bakhtin, é dialógica porque implica um processo no qual outros enunciados entram em contato e o confrontam: "para cada palavra do enunciado que estamos em processo de compreender, propomos, por assim dizer, um conjunto de palavras nossas como resposta" (BAKHTIN, 2009, p. 132). Nessa relação dialógica, onde, muitas vezes, durante a entrevista, ocorre uma interferência do pesquisador no enunciado do pesquisado para tentar compreender algo que não é dele, mas do outro, chegamos no processo ao que denominamos achados de pesquisa e não resultados. 


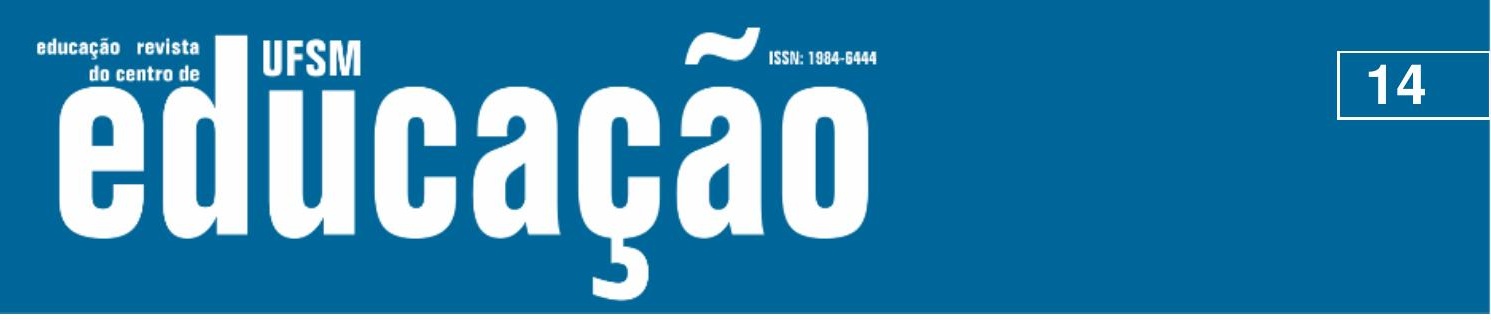

ISSN: 1984-6444 | http://dx.doi.org/10.5902/1984644436687

Bakhtin (2008) compreende a linguagem, assim como o homem e a vida, marcada pelo dialogismo ${ }^{3}$. Na relação dialógica entre investigador e pesquisados, os sentidos vão sendo arquitetados. Nela, o pesquisador não chega a resultados acabados e generalizáveis para qualquer situação já que estes são constituídos em contextos particulares de investigação, e a dinâmica é a compreensão dos fenômenos estudados na singularidade das situações em que foi produzida.

Nessa perspectiva, o pesquisador constrói sentidos a partir de sua experiência com os sujeitos participantes no campo de pesquisa. O encontro que se dá é com o outro na investigação, e as diversas vozes repercutem sentidos variados e visões diferentes de mundo que lançam a uma compreensão ativa e responsiva, conforme Bakhtin:

O sentido é potencialmente infinito, mas pode atualizar-se somente em contato com outro sentido (do outro), ainda que seja com uma pergunta do discurso interior do sujeito da compreensão. Ele deve sempre contatar com outro sentido para revelar os novos elementos da sua perenidade (como a palavra revela os seus significados somente no contexto). Um sentido atual não pertence a um (só) sentido, mas tão-somente a dois sentidos que se encontraram e se contataram. Não pode haver "sentido em si" - ele só existe para outro sentido, isto é, só existe com ele. Não pode haver um sentido único (um). Por isso não pode haver o primeiro nem o último sentido, ele está sempre situado entre os sentidos, é um elo na cadeia dos sentidos, a única que pode existir realmente em sua totalidade (BAKHTIN, 2011, p. 382).

Desse modo, o princípio dialógico permeia toda produção discursiva. Para Bakhtin (2009), as pessoas se comunicam dialogicamente, as peculiaridades enunciativas de uma dada circunstância dialógica situam-se no processo interativo verbal e não verbal. Na interação verbal, o indivíduo expressa-se e interage, esta expressão comporta duas facetas: o conteúdo (interior) e sua objetivação exterior para outrem (ou para si mesmo) e, ao exterioriza-se, o conteúdo interior muda de aspecto, pois é obrigado a apropriar-se do material exterior.

Para o mesmo autor (2009, p. 113), a verdadeira substância da língua constitui-se na interação verbal que se realiza na enunciação. A palavra (enunciado), em sua natureza dialógica, não é um objeto e sim um meio constantemente ativo e mutável de comunicação. O enunciado é visto por Bakhtin como a unidade da comunicação discursiva. Cada enunciado constitui um novo acontecimento, um 


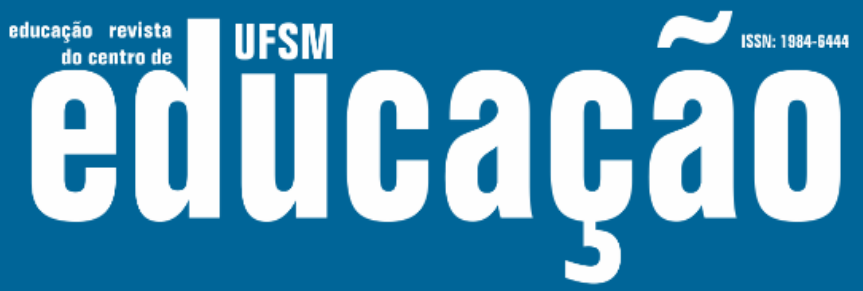

ISSN: 1984-6444 | http://dx.doi.org/10.5902/1984644436687

evento único e irrepetível da comunicação discursiva. Ele só pode ser citado e não repetido, pois, nesse caso, se constitui como um novo acontecimento. $O$ enunciado nasce na inter-relação discursiva, por isso que não pode ser nem o primeiro nem o último, pois já é resposta a outros enunciados, ou seja, surge como sua réplica.

É no processo de relação social que a palavra vive, "a palavra é o modo mais puro e sensível de relação social", o que revela a importância que o autor dá à natureza social dos fatos linguísticos (BAKHTIN, 2009, p. 36). Sendo assim, nessa relação dialógica, uma palavra só não é suficiente, são necessárias sempre, pelo menos, duas vozes. Por este motivo, a ideia que o autor traz sobre a palavra comporta duas faces, ou seja, por ser determinada tanto pelo fato de que precede de alguém, como pelo fato de que se dirige para alguém.

Nesse sentido, o eu daquele que narra pode ser o porta voz de muitas outras vozes e não ser apenas aquele que se enuncia. Nessa direção, apontamos que o pensamento bakhtiniano tem uma concepção de linguagem fundamentada numa abordagem histórica, cultural e social. Desse modo, o enunciado é apresentado por Bakhtin inserido na história, na cultura, na sociedade, isto é, a linguagem emerge a partir da vida do homem e "a enunciação é de natureza social" (BAKHTIN, 2009, p. 109).

Bolzan (2002, p.48), que tem como referência os estudos de Bakhtin, aponta que:

Todo o enunciado é um diálogo que faz parte de um processo de comunicação contínuo. Não há enunciado isolado, todo enunciado é parte de um conjunto, podendo somente ser compreendido no interior desse conjunto. Nesse sentido, o diálogo representa uma "réplica" do já dito no fluxo da comunicação. O diálogo acontece à medida que as muitas vozes, através dos ditos, se encontram, ou seja, a interação verbal se constitui num fenômeno social.

Dessa forma, o dialogismo não é apenas a orientação da palavra ao outro, mas o embate, no enunciado, das vozes ideológicas de um grupo social, num momento e lugar historicamente determinados. Podemos também ressaltar o conceito de alteridade de Bakhtin (2008), uma vez que, na concepção do autor, o homem emerge do outro homem e somente ao se revelar para o outro é que se 


\section{Authaดูã}

ISSN: 1984-6444 | http://dx.doi.org/10.5902/1984644436687

torna ele mesmo. Aqui podemos pensar, portanto no pesquisador como um dos principais instrumentos da pesquisa.

O enunciado é a expressão de um ponto de vista, de uma voz que se dirige a outra, produzido num contexto social e extraverbal, possibilitando tantos sentidos quanto os diversos contextos em que ocorra. A experiência individual do enunciado forma-se e desenvolve-se em uma constante interação com os enunciados individuais alheios, sendo algo que faz a ligação dentro de uma cadeia de enunciados que the antecedem e the sucedem. Todo enunciado é composto por relações dialógicas e, quando é possível ouvir essas vozes, num dado momento e lugar, dando origem a uma pluralidade de sentidos, temos um caso de polifonia.

Como aborda Bolzan (2009, p. 73-74):

A complexidade da narrativa leva os investigadores a levantarem 0 problema dos múltiplos EUS - polifonia. Durante a narração, os múltiplos "eus" emergem em função dos múltiplos papéis que o investigador e os participantes assumem. Podemos ser um eu que fala como investigador, como participante da investigação, como crítico narrativo, como construtor de teorias, como estímulo auxiliar, etc. Entretanto, quando vivemos o processo de investigação narrativa, somos apenas uma pessoa.

A perspectiva narrativa sociocultural coloca o sujeito como produtor de um conhecimento de si, sobre os outros e sobre a sua prática e processo de formação, e isso se revela mediante a subjetividade, a singularidade, as experiências e os saberes que foram se construindo no percurso espaço-temporal de sua vida pessoal e profissional. Nessa perspectiva, é atribuído ao professor o papel de sujeito do estudo, ao mesmo tempo em que a narrativa sociocultural, que tem como instrumento de coleta de dados a entrevista semiestruturada com os docentes, pode possibilitar ao professor investigar sua própria prática e produzir seus saberes, o que contribui para o seu desenvolvimento pessoal e profissional e aprendizagem da docência.

Nesse sentido, vemos que a narrativa não é um simples narrar de acontecimentos, mas algo que envolve e possibilita tanto a reflexão quanto a tomada de consciência. 


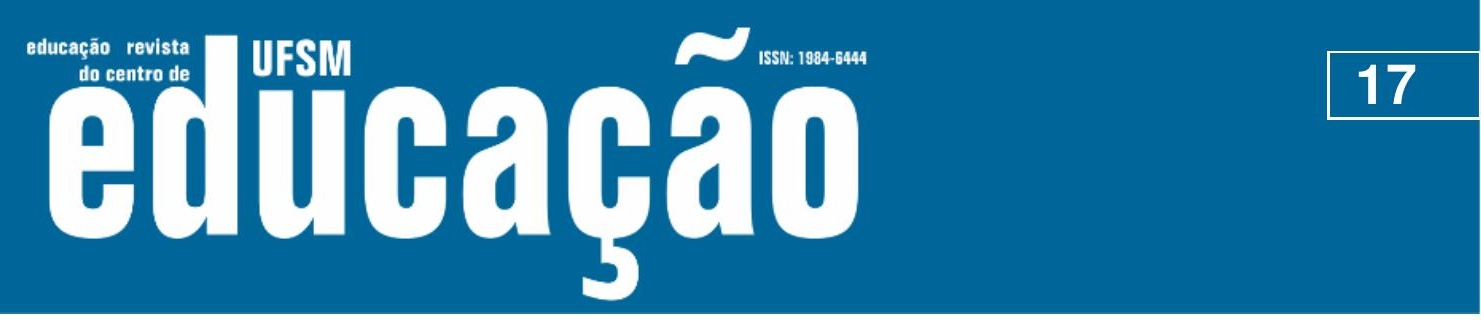

ISSN: 1984-6444 | http://dx.doi.org/10.5902/1984644436687

Eu tomo consciência de mim e me torno eu mesmo unicamente me revelando para o outro, através do outro e com o auxílio do outro. Os atos mais importantes, que constituem a autoconsciência, são determinados pela relação com outra consciência (com o tu) (BAKHTIN, 2011, p. 341).

Connelly e Clandinin (1995) lembram-nos de uma especificidade importante acerca das narrativas: a temporalidade. Ressaltam que o tempo é um elemento que não pode ser desconsiderado em pesquisas que utilizam narrativas, pois, ao narrar uma história, o autor-narrador articula a tríade temporal: presente, passado e futuro. Nesse sentido, os autores discorrem que a vida pessoal e profissional é repleta de fragmentos narrativos, que determinam trajetórias de tempo e espaço dos pesquisadores e colaboradores da pesquisa. É possível compreender a experiência desses sujeitos de maneira contínua e interativa, de forma a buscar a subjetividade, as singularidades e as particularidades, que ao narrar, o sujeito explicita os processos educacionais que constituem a sua trajetória, demonstrando momentos de continuidade e descontinuidade, de rupturas e [re]significações da experiência e da aprendizagem humana.

Por isso, a importância dessa abordagem e de seus instrumentos e procedimentos e base epistemológica está no fato de proporcionar a compreensão do processo de transformação que é explicitado pelas narrativas dos professores. Sendo assim, devemos buscar compreender o indivíduo como um ser determinado histórica e socialmente. Temos que ter em mente que esse indivíduo que narra jamais poderá ser compreendido senão por suas relações e seus vínculos sociais, em sua inserção em determinada sociedade, em um momento histórico específico.

\section{Alguns apontamentos finais}

No decorrer desta escrita, verificamos que a pesquisa educacional foi marcada por uma mudança do paradigma quantitativo na direção de abordagens qualitativas. As formulações teóricas e as explicações científicas no campo da educação possibilitaram emergir novas abordagens metodológicas, entre elas a abordagem qualitativa narrativa de cunho sociocultural.

Este tipo de investigação caracterizada como estudo qualitativo-narrativo fundamentado na abordagem sociocultural foi ampliado nos últimos anos, 


\section{Authaดูã}

ISSN: 1984-6444 | http://dx.doi.org/10.5902/1984644436687

principalmente em pesquisas de mestrado e doutorado. Essa abordagem tem se firmado como promissora possibilidade de investigação em pesquisas realizadas na área da educação. As investigações baseadas nela possibilitam a compreensão do processo de transformação, sob seu aspecto histórico e de mudança, no qual os sujeitos que narram estão envolvidos.

Cabe destacarmos que, neste artigo, nos limitamos a trazer apenas algumas considerações sobre a perspectiva da abordagem narrativa de cunho sociocultural. Ainda se faz necessária nos estudos desta natureza, uma discussão em profundidade, assim como uma explicação mais detalhada sobre os procedimentos de organização e de sistematização do processo de análise das narrativas socioculturais, o que podemos considerar algo complexo, pois requer atenção do pesquisador e necessita ser coerente com a escolha do referencial teórico metodológico adotado.

Com isso, precisamos ter clareza de que, ao optarmos por uma abordagem de pesquisa, no momento em que vamos empreender o método, precisamos de detalhamento e de sustentação teórica, o que nos exige compreensão e certo rigor nos cuidados investigativos, "o que não quer dizer seguimento de rígidos protocolos, mas, sim de domínio flexível de métodos e instrumentos necessários à aproximação significativa do real" (GATTI e ANDRE, 2009, p. 37). Essa constatação, portanto parte do entendimento, que as abordagens qualitativas trazem um grau de exigência grande para o trato com a realidade e sua reconstrução, pois envolve pesquisador e colaboradores do estudo, que ao estabelecerem um diálogo tendem a compreender o enunciado de forma responsiva, a qual a linguagem se torna interativa e passa a ser compreensiva entre as partes.

\section{Referências}

ALHEIT, P.; DAUSIEN, Bettina. Processo de formação e aprendizagens ao longo da vida. Educ. Pesqui. vol.32, n.1 São Paulo Jan./Apr. 2006.

ALHEIT, P.; DAUSIEN, Bettina. Bildung als "biographische konstruktion"? Nichtintendierte lernprozesse in der organisierten erwachsenenbildung. Report. Literatur- und Forschungsreport Weiterbildung, v. 37, p. 33-45. 1996. 


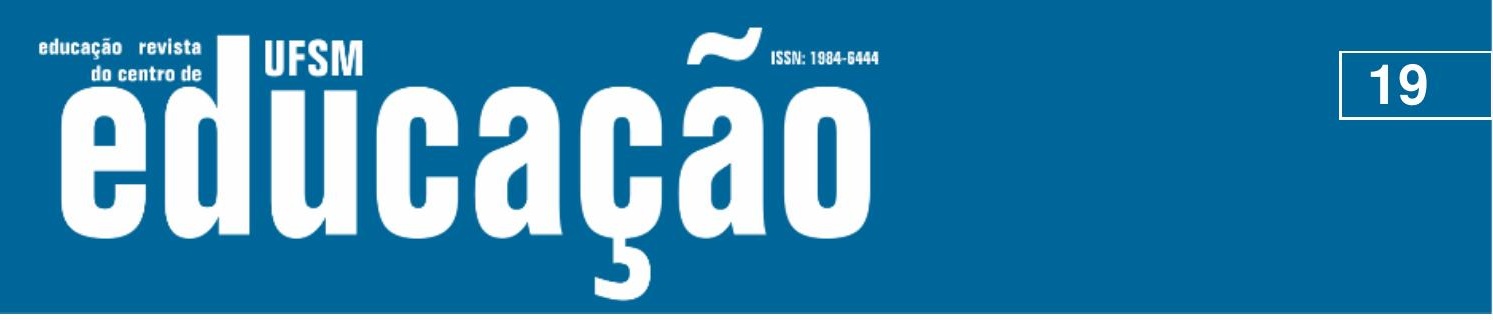

ISSN: 1984-6444 | http://dx.doi.org/10.5902/1984644436687

BAKHTIN, Mikhail. Estética da criação verbal. 6. ed. São Paulo: Martins Fontes, 2011.

BAKHTIN, Mikhail. Problemas da Poética de Dostoiévski. 4. ed. Rio de Janeiro: Forense Universitária, 2008 (Originalmente publicado em 1936).

BAKHTIN, Mikhail. Marxismo e filosofia da Linguagem. 15. ed. São Paulo: Hucitec/Annablume, 2009.

BAKHTIN, Mikhail. Para uma filosofia do Ato Responsável. São Carlos: Pedro \& João Editores, 2010.

BERTAUX, Daniel (Ed.) Biography and society. The life history approach in the social sciences. Beverly Hills: Sage publications, 1981.

BOCK, Ana Mercês Bahia. A psicologia sócio-histórica: uma perspectiva crítica em psicologia. In: Bock, Ana Mercês Bahia; Gonçalves, Maria da Graça Marchina.; Furtado, O. (Orgs.). Psicologia sócio-histórica: uma perspectiva crítica em psicologia. São Paulo: Cortez, 2007.

BOCK, Ana Mercês Bahia; FURTADO, Odair; TEIXEIRA, Maria De Lourdes Trassi. Psicologias: uma introdução ao estudo da psicologia. 14. ed. São Paulo: Saraiva, 2008.

BOLZAN, Doris Pires Vargas. A construção do conhecimento pedagógico compartilhado: um estudo a partir de narrativas de professoras do ensino fundamental. 2001. 268f. (Doutorado em Educação) - Universidade Federal do Rio Grande do Sul, Porto Alegre, 2001.

BOLZAN, Doris. Pires Vargas. Formação de professores: compartilhando e reconstruindo conhecimentos. Porto Alegre: Mediação, 2002.

BOLZAN, Doris Pires Vargas. Abordagem narrativa sociocultural. In: MOROSINI, M. C. (Org.). et al. Enciclopédia de Pedagogia Universitária.Brasília, DF: INEP/RIES, 2006. Glossário v. 2. p. 386.

BOLZAN, Doris Pires Vargas. Formação de professores: compartilhando e reconstruindo conhecimentos.2. ed. Porto Alegre: Mediação, 2009a.

BOLZAN, Doris Pires Vargas; POWACZUK, Ana Carla Hollweg. Docência universitária: A Construção da professoralidade. Revista Brasileira de Formação de Professores - RBFP, Cristalina: Autores Associados, v. 1, n. 3, p. 90-104, dez. 2009b.

Disponível

em:

http://www.facec.edu.br/seer/index.php/formacaodeprofessores/article/viewFile/113/1 62. Acesso em: 12 out. 2014.

BONIN, Luiz Fernando Rolim. A teoria histórico-cultural e condições biológicas. 1996. Tese (Doutorado em Psicologia Social)-Pontifícia Universidade Católica de São Paulo, São Paulo,1996. 


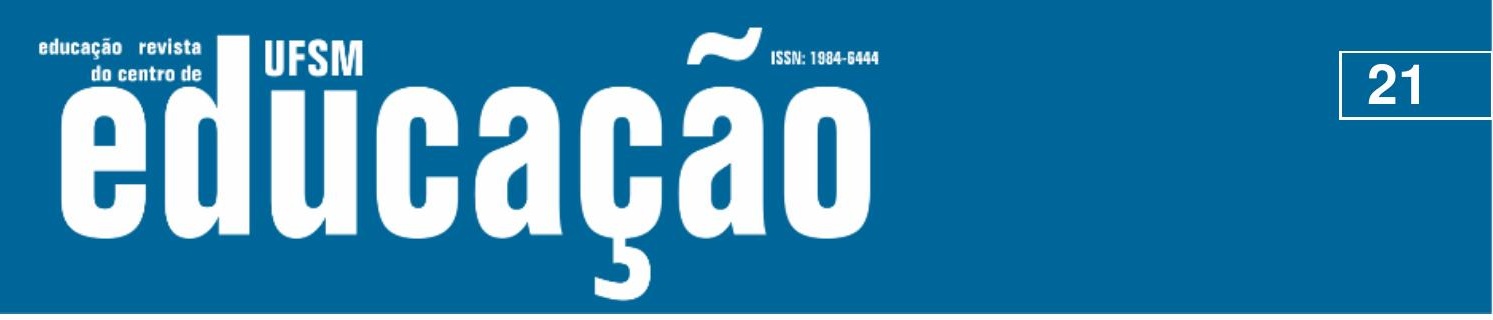

ISSN: 1984-6444 | http://dx.doi.org/10.5902/1984644436687

HELLER, Agnes. Sociologia de la vida cotidiana. Impresso em Nova-grafick s/a., Puigcerd127, 08019- Barcelona, 1991.

ISAIA, Silvia Maria de Aguiar. Investigação narrativa. In: MOROSINI, Marília Costa (Org.) et al. Enciclopédia de pedagogia universitária. Brasília, DF: INEP/RIES, 2006. Glossário v. 2. p. 385.

ISAIA, Silvia Maria de Aguiar; BOLZAN, Doris Pires Vargas. Construção da profissão docente: possibilidades e desafios para a formação. In: ISAIA, Silvia Maria de Aguiar; BOLZAN, Doris Pires Vargas; MACIEL, Adriana Moreira da Rocha (Org.). Pedagogia universitária tecendo redes sobre a educação superior. Santa Maria: Ed. UFSM, 2009. p. 163-176.

ISAIA, Silvia Maria de Aguiar. Movimentos construtivos da docência/aprendizagem: tessituras formativas. In: ENCONTRO NACIONAL DE DIDÁTICA E PRÁTICA DE ENSINO: Endipe, 15., 2010, Belo Horizonte. Anais Endipe 15. Belo Horizonte: UFMG, $2010 . \quad$ v. $1 . \quad$ p. $1-14 . \quad$ Disponível em: http://w3.ufsm.br/kosmos/textos/baprendizagem\%20docente.pdf. Acesso em: 21 out. 2014.

LÜDKE, Menga; ANDRÉ, Marli. Pesquisa em educação: abordagens qualitativas. São Paulo: EPU, 1986.

MINAYO, Maria Cecília de Souza. (Org.). Pesquisa social: teoria, método e criatividade. Petrópolis: Vozes, 2001.

POWACZUK, Ana Carla Hollweg. Movimentos da professoralidade: a tessitura da docência universitária. 2012. 219 f. Tese (Doutorado em Educação)-Universidade Federal de Santa Maria, Santa Maria, 2012.

VYGOTSKY, Lev Semyonovich. Pensamento e Linguagem. São Paulo: Martins Fontes, 2008.

VYGOTSKY, Lev Semyonovich. Obras Escogidas III: incluye problemas del desarrollo de la psique. Madri-Espana.Visor, 1995.

VYGOTSKY, Lev Semyonovich. A Formação Social da Mente. São Paulo: Martins Fontes, 2007.

WERTSCH, James V. Voces de la mente: um enfoque sociocultural para el estúdio de la acción mediada. Madrid: Visor Distribuciones, 1993.

\section{Correspondência}

Silvana Zancan- Universidade Federal de Santa Maria - Av. Roraima no 1000 Cidade Universitária Bairro, Camobi, CEP 97105-900, Santa Maria, Rio Grande do Sul, Brasil. 


\title{
$\sim$

ISSN: 1984-6444 | http://dx.doi.org/10.5902/1984644436687

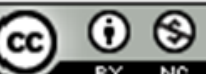

\section{This work is licensed under a Creative Commons Attribution-NonCommercial 4.0 International (CC BY-NC 4.0)}

\section{Notas}

\begin{abstract}
${ }^{1}$ Optamos por denominar atividade discursiva/narrativa por entendermos que com o diálogo, estabelecem-se as interações de vozes, as palavras vão sendo ditas, de forma a configurar uma comunicação. A narração de determinados fatos e trajetórias de vida de sujeitos não é neutra, pois cada enunciado constitui outros enunciados definidos pela alternância dos sujeitos do discurso.

${ }^{2}$ Tradução: [...] estudar algo historicamente significa estudá-lo em movimento. Esta é a exigência fundamental do método dialético. Quando em uma investigação se utiliza o processo de desenvolvimento de algum fenômeno em todas as suas fases e mudanças desde a origem até que desaparece, isto implica em deixar visível sua natureza, conhecer sua essência, já que só em movimento mostra o corpo que existe. Assim, pois, a investigação histórica da conduta não é algo que complementa ou ajuda o estudo histórico, mas o que constitui o seu fundamento (VYGOTSKY, 1995, p. 67- 68).
\end{abstract}

${ }^{3}$ A noção de dialogia pressupõe que em todo enunciado há duas vozes, mesmo que não haja interação. 